\title{
IKLAN ENAMEL DAN PENGGAMBARAN PERUBAHAN KOTA DI ZAMAN HINDIA BELANDA
}

\author{
Karina Rima Melati \\ Dosen Akademi Komunikasi Indonesia “AKINDO" Yogyakarta, \\ Email: karinarimamelati@gmail.com
}

\section{ABSTRACT}

Ads enamel is present as part of a media phenomenon in the world of advertising communication made with a complex reproductive techniques and has a characteristic that distinguishes it from other advertising media. Factors affecting the visual content of the message in the repertoire of developmental enamel advertising in Indonesia, developed along with the progress especially in the areas of economy, as well as an attempt penetration with idioms - idioms to suit its target market.

The next development was the emergence of new ideas in making an alternative advertisement-based enamel, such as the packaging of food products (packaging), ashtrays, trays or trays, seat backrest, backrest calendar, memo backrest, clocks, thermometers and so giant that created with an attractive design.

Keywords: Ads enamel, Delineation change the city, Past the Dutch East Indies

\section{Pendahuluan}

Transformasi perkotaan di Jawa pada awal abad ke-20 menunjukkan bentuknya yang dinamis dengan konsepsi tentang modernisme. Modernisme di masa Hindia Belanda tersebut merangkul ide-ide yang dianggap baru, meskipun yang lama masih selalu bisa menjadi sumber untuk formasi baru. Semangat yang diusung adalah menciptakan tatanan simbolik baru terutama menghadirkan ekspresi tentang komersialisasi di tengah-tengah perkotaan. Paling tampak menonjol dari perkembangan ini adalah munculnya bangunan-bangunan dengan arsitektur modern dan berbagai atribut perkotaan sebagai pendukungnya (Mrazek, 2002:73). Pengadaan infrastruktur perkotaan oleh pemerintah kolonial Belanda saat itu ditunjukkan dengan pembangunan fasilitas perkotaan yang mengembangkan berbagai solusi bagi masyarakat Jawa (Mrazek: 84).

Kontras dengan kondisi sebelum peralihan abad di mana pasca perang Jawa oleh Dipenegoro (1825-1830) memaksa pemerintah kolonial yang saat itu nyaris bangkrut, untuk menerapkan tanam paksa bagi sebagian besar pribumi agar menghasilkan keuntungan baru. Diakhir abad 19 karena desakan kaum sosialis baik di Hindia maupun di Belanda, sistem tanam paksa itu dihentikan dan berganti dengan politik etis atau politik balas budi yang mengusahakan terjadinya pemerataan kesejahteraan penduduk (Gauda, 2007:57). Melaui pembangunan perkotaan dengan segala fasilitas yang sudah disinggung di paragraf sebelumnya, yang juga menonjol dari zaman transformasi saat itu adalah munculnya industrialisasi dengan produk komoditasnya yang menseduksi masyarakat melalui tampilan, fungsi, serta penyebaran informasi mengenai produk tersebut yang terhitung baru dan massif.

Penyebaran informasi kepada target audience dianggap penting karena keberadaan produk-produk baru tersebut masih asing sehingga calon konsumen diberikan konsep terutama terkait dengan nilai fungsi dari produk tersebut. Iklan menjadi pesan informatif yang banyak digunakan oleh produsen untuk memperkenalkan produknya. Salah satunya adalah dengan iklan media luar 
ruang berbahan plat besi, enamel. Performa iklan enamel yang berwarna cerah, kuat terhadap berbagai cuaca, tahan lama, dinilai efektif untuk dijadikan sumber informasi produk. Kesan modern juga sangat tampak pada iklan enamel karena pembuatanya menggunakan mesin berteknologi canggih yang hanya dapat dibuat di Eropa. Selain itu iklan enamel juga mengimbangi atau menjadi media pendukung poster kertas maupun iklan cetak koran yang mudah sobek dan hanya bersifat sementara.

Sepanjang jalan di perkotaan modern kemudian diperlihatkan tanda-tanda zaman modernisme dengan iklan enamel yang menempel pada bangunan-bangunan modern. Maka saat itu mulai terurai proses transformasi ke tatanan simbolik baru dengan kota dengan wajah arsitektur modernis yang dihiasi oleh iklan enamel sebagai artefak budayanya. Pertanyaan kemudian: Bagaimana iklan enamel menunjukkan dinamika perubahan zaman lama ke modern terutama di kota-kota besar di Jawa pada era Hindia Belanda? Kemudian bagaimana iklan enamel menjadi embrio iklan media luar ruang yang berkaitan lansung dengan wajah ruang publik kota-kota yang ditempatkannya?

\section{Sejaran Iklan Enamel}

Istilah 'enamel' mengacu pada suatu teknik dekorasi yang meleburkan (to smelt) bubuk kaca diatas lempengan besi-baja bermutu tinggi pada sebuah oven dengan temperatur tinggi. Bubuk tersebut kemudian mengurai hingga menyatu dan menjadi keras. Proses pengerasan tersebut disesuaikan dengan tampilan visual dan warnanya. Pembuatan iklan enamel harus dilakukan secara khusus, diawali dengan pengaplikasian desain menjadi stensil atau screen per-warna kemudian disablon ke lempengan besi dengan penggunaan cat bakar khusus enamel (berbentuk butiran atau cairan) dan dipanaskan dengan temperatur panas yang tinggi antara $760 \mathrm{C}$ 850C (Baglee \& Morley, 1979:15-16). Proses sablon dan pemanasan dilakukan berulang-ulang menurut desain (warna) yang ingin dihasilkan. Diawali dari warna cerah / kuat karena paling banyak menerima pembakaran dan diakhiri dengan warna lembut untuk menghindari warna akan pudar atau hilang. Iklan enamel memiliki ketebalan 2-3 milimeter, dengan karakteristik warna yang sangat kuat serta tahan lama. Pada banyak iklan enamel, warna pada desain ditandai dengan adanya tekstur yang menonjol dan jika dipegang atau diraba akan terasa pembedaan warnanya.

Kehadiran iklan enamel dimulai di Inggris oleh Benjamin Bough yang mendirikan perusahaan pertama pembuat papan enamel bernama "Patent Enamel Company Limited". Awalnya iklan enamel masih sangat terbatas bahkan termarjinalkan secara konteks peradabannya terutama karena bahan baku serta proses pembuatan rumit sehingga tidak banyak dilirik sebagai jenis usaha pembuatan atau produksi iklan yang mudah dikeluti. Terjadinya revolusi industri yang dinamis di dataran Eropa pada akhir abad ke 19, menuntut perbaikan media komunikasi agar dapat mendorong tumbuh kembangnya industri tersebut. Proses enamel kemudian diaplikasikan untuk membuat lempengan iklan karena dianggap dapat menjawab tantangan akan keawetan serta kekuatan beriklan modern, dalam hal ini media iklan luar ruang. Selain juga karena pada saat itu produk-produk komoditas masih sedikit jenisnya atau belum terjadi kompetisi produk sejenis, maka keawetan dan kekuatan iklan enamel dibuat agar dapat bertahan lama tanpa harus mempertimbankan kebaruan desain. 


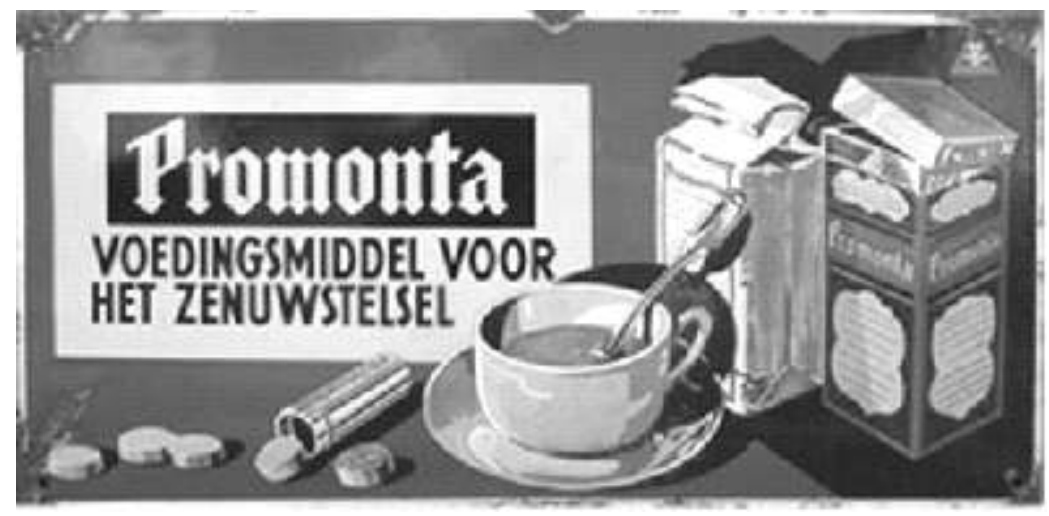

Gambar 1. Performa iklan enamel Promonta yang merupakan produk dengan menerapkan metode pembuatan modern, dimana produk dibuat tablet atau di padatkan untuk kemudian dapat dinikmati dengan dilarutkan dalam zat cair atau air. Promonta terdiri dari bentuk tablet effervescent dan bubuk, produk ini yang juga berfungsi sebagai suplemen untuk perbaikan syaraf kemudian menjadi indikasi munculnya produk sejenis dengan kegunaan yang berbeda-beda. Arti pada tagline dalam bahasa Indonesia: "Minuman/makanan tambahan atau suplemen untuk (perbaikan) urat saraf.'

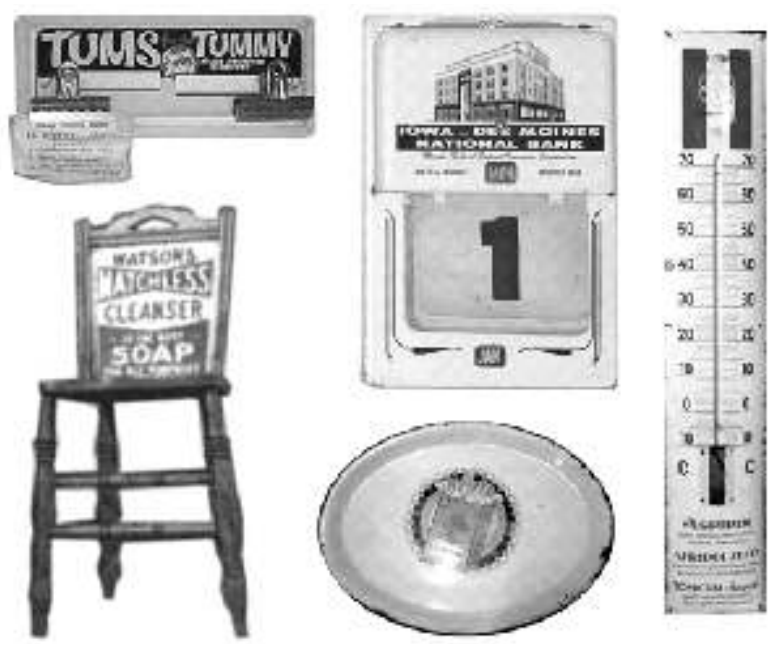

Gambar 2. Beberapa contoh penerapan enamel pada beberapa media iklan. Khusus giant termometer produk Bayer (paling kanan) memiliki ketinggian hinggal meter serta dilengkapi juga dengan air raksa yang sanggup mengukur panas udara,termometer tersebut biasa diletakkan di toko obat.
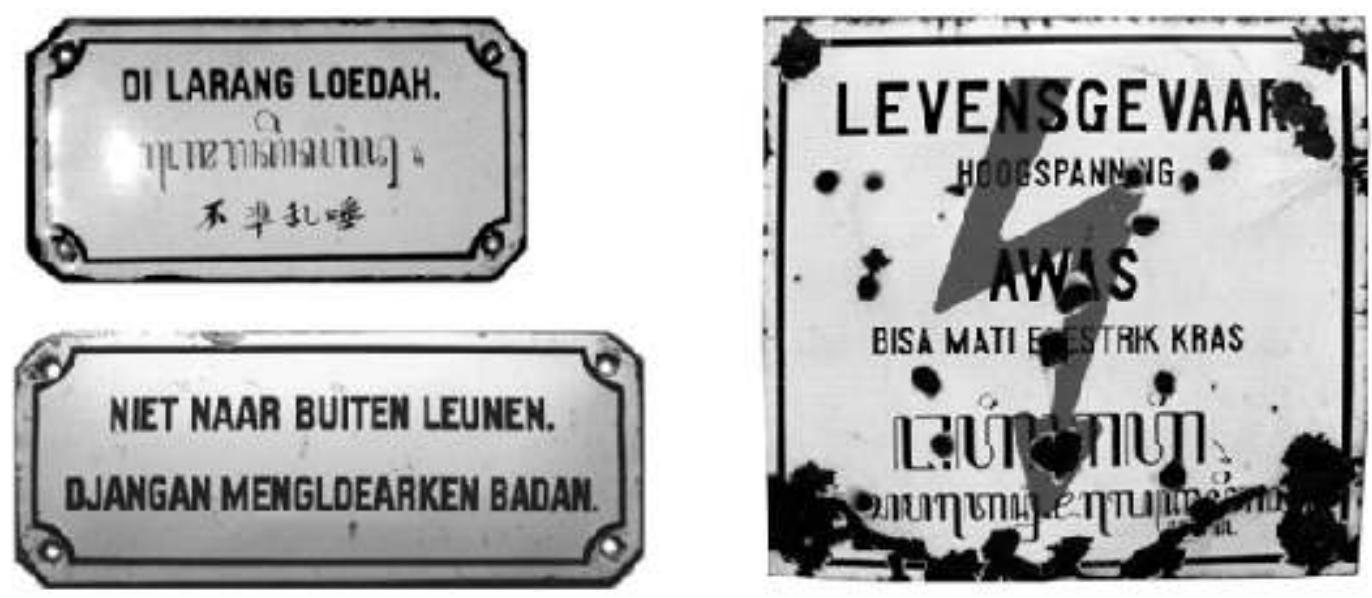

Gambar 3: Beberapa contoh penerapan enamel untuk peraturan di fasilitas publik. 
Iklan enamel hadir sebagai bagian dari fenomena media komunikasi di dunia periklanan yang dibuat dengan teknik reproduksi yang rumit serta memiliki ciri khas yang membedakannya dengan media iklan lain. Faktor visual yang mempengaruhi isi pesan dalam khasanah perkembangan iklan enamel di Indonesia, berkembang seiring dengan kemajuan terutama di bidang perekonomian, sekaligus sebagai usaha penetrasi dengan idiom - idiom yang sesuai dengan target pasarnya.

Perkembangan selanjutnya adalah munculnya gagasan-gagasan baru dalam membuat alternatif iklan berbahan dasar enamel, seperti pada kemasan produk makanan (packaging), asbak, nampan atau baki, sandaran tempat duduk, sandaran kalender, sandaran memo, jam, giant thermometer dan sebagainya yang dibuat dengan desain yang menarik.

Gejala Modernitas pada Barang-barang Komoditas

Adanya industrialisasi melibatkan hampir seluruh komponen masyarakat untuk bergabung padanya. Hal ini menimbulkan peningkatan perekonomian liberal serta membuka kegiatan perdagangan termasuk bagi kelompok pribumi. Terjadinya perubahan stratanisasi sosial kemasyarakatan di Hindia yang awalnya menganut paham feodal tradisional yang kental, bergeser menjadi masyarakat modern yang konsumtif (Nordholt, 2011:451). Hal ini termasuk terjadinya perubahan nilai konstruksi barangbarang dan jasa, yang kemudian ditransformasikan menjadi komoditas. Dengan demikian kesadaran popular dari struktur hubungan sosial ditentukan oleh bentuk-bentuk komoditas yang baru.
Imigran dari Eropa terutama Belanda tidak hanya menghadirkan populasi masyarakat baru di Hindia, namun menjadi faktor pendukung peradaban baru munculnya perkotaan modern yang ditopang dengan masuknya segala produk industri komoditas modern diimport khususnya dari Eropa yang menawarkan pelayanan dan nilai tambah baru dari pemanfaatannya (Nordholt, 2011:447). Pembangunan fasilitas sarana dan prasarana umum seperti bangunan gedung-gedung mewah, bangunan rumah bergaya kolonial atau "kampung Belanda", pusat perdagangan, sekolah, bank, perkantoran, pengadaan transportasi modern, industrialisasi yang meluas telah menjadi jamak dilakukan pada saat itu terutama bahwa Belanda ingin menciptakan sebuah sistem pendukung pemerintahan yang juga diterapkan di negara induk mereka di Eropa (Riyanto, 2000:139).

Generasi muda, tinggal di perkotaan, berpendidikan a la barat, menjadi figur yang paling tepat untuk dijadikan target audience bagi barangbarang komoditas yang baru. Tak heran saat itu penampilan kebarat-baratan, pemakaian barangbarang import kebutuhan sehari-hari, mesin-mesin yang menggatikan pekerjaan manual, menjadi semakin umum dan prestis tersendiri bagi pemakainya. Puncaknya adalah dengan adanya pendidikan modern barat (Politik Etis) memegang peranan penting pada perubahan pola masyarakat di Hindia, khususnya bagi para priyayi terpelajar yang kemudian menjadi agen of change penerapan gaya hidup barat (Riyanto:200). Mereka sekaligus menjadi role model bagi kelompok sosial masyarakat baru.

Penggunaan pakaian barat dengan adegan merokok sigaret putih seperti tampak pada 

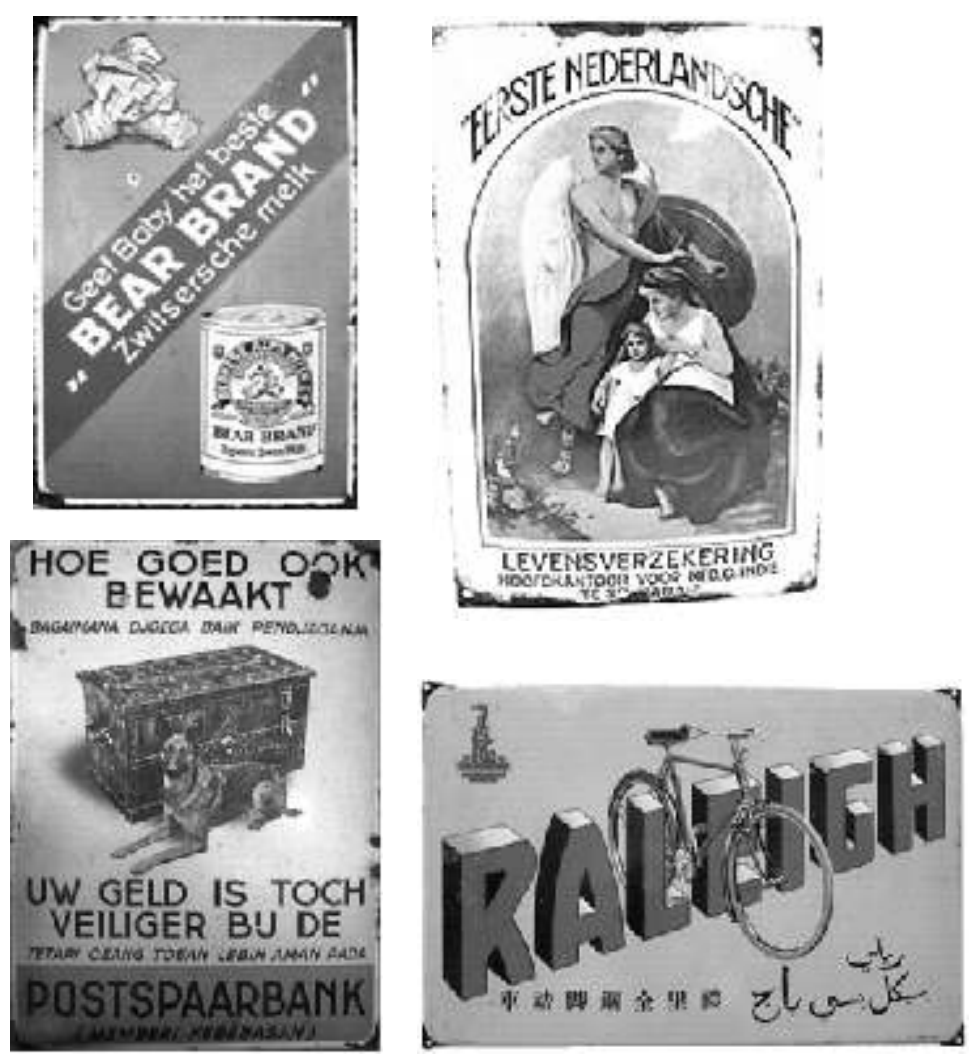

Gambar 4 a-d (searah jarum jam): Performa iklan enamel bagi target audience masyarakat Eropa yang tinggal di Hindia. Meski demikian, pada waktu selanjutnya iklan enamel juga ditujukan dengan penggunaan bahasa melayu, arab pegon dan mandarin.

Gambar a : Arti pada tagline dalam bahasa Indonesia "Berikan bayi anda yang terbaik"

Gambarb : Arti pada tagline dalam bahasa Indonesia "Jadilah Orang Belanda Pertama (untuk berasuransi)"“Yang menjamin hidup anda". "Kantor pusat untuk Hindia Belanda" "di Surabaya”.

Gambarc : Arti pada tagline dalam bahasa Indonesia 'Raleigh Basikal, (dari kata Bicycle (Inggris) yang artinya sepeda) besi baja'.

Gambard : Arti pada tagline dalam bahasa Indonesia "Bagamana juga baik penjagaannya”. "Tetapi uang tuan lebih aman pada POSTSPAARBANK

iklan gambar 5b menjadi simbol kelas elit pribumi bagi pemakainya. Peci atau kopiah juga dibuat sebagai identitas kelokal-an yang masih dipertahankan, sebab meski gaya hidup barat telah menjadi obsesi tersendiri bagi para prubumi, namun sifat kedaerahan atau kepribadian bagsa (local genius) (Taylor, 2005:162) tidak secara nyata tenggelam dalam hangar bingar kemewahan yang ditawarkan gaya hidup barat, hingga keadaan seperti itu justru menjadi dialog antar kebudayaan, dimana dua kebudayaan saling transfer menjadi satu hibrida kebudayaan yang baru, dan hal tersebut menjadi fenomena representasi iklan pada pertengahan abad ke-20.
Meski demikian, dengan semakin banyaknya kaum terpelajar menyadarkan mereka untuk membebaskan diri dari belenggu kolonialisme. Mereka ini adalah kaum pendobrak, avant-gardis yang juga ingin masuk ke dalam arus modernitas dengan hiruknya industrialisasi yang segalanya tiba-tiba mudah dengan barang komoditas. Lebih lanjut dengan produk-produk komoditas baru tersebut dapat dimaknai atau berfungsi ganda: ingin merangkul individuindividu yang berhasrat modern sekaligus menghindarkan mereka supaya tidak menjadi pergerakan anti kolonial. Singkatnya modernitas bagi pemerintah kolonial Belanda, seharusnya bisa 

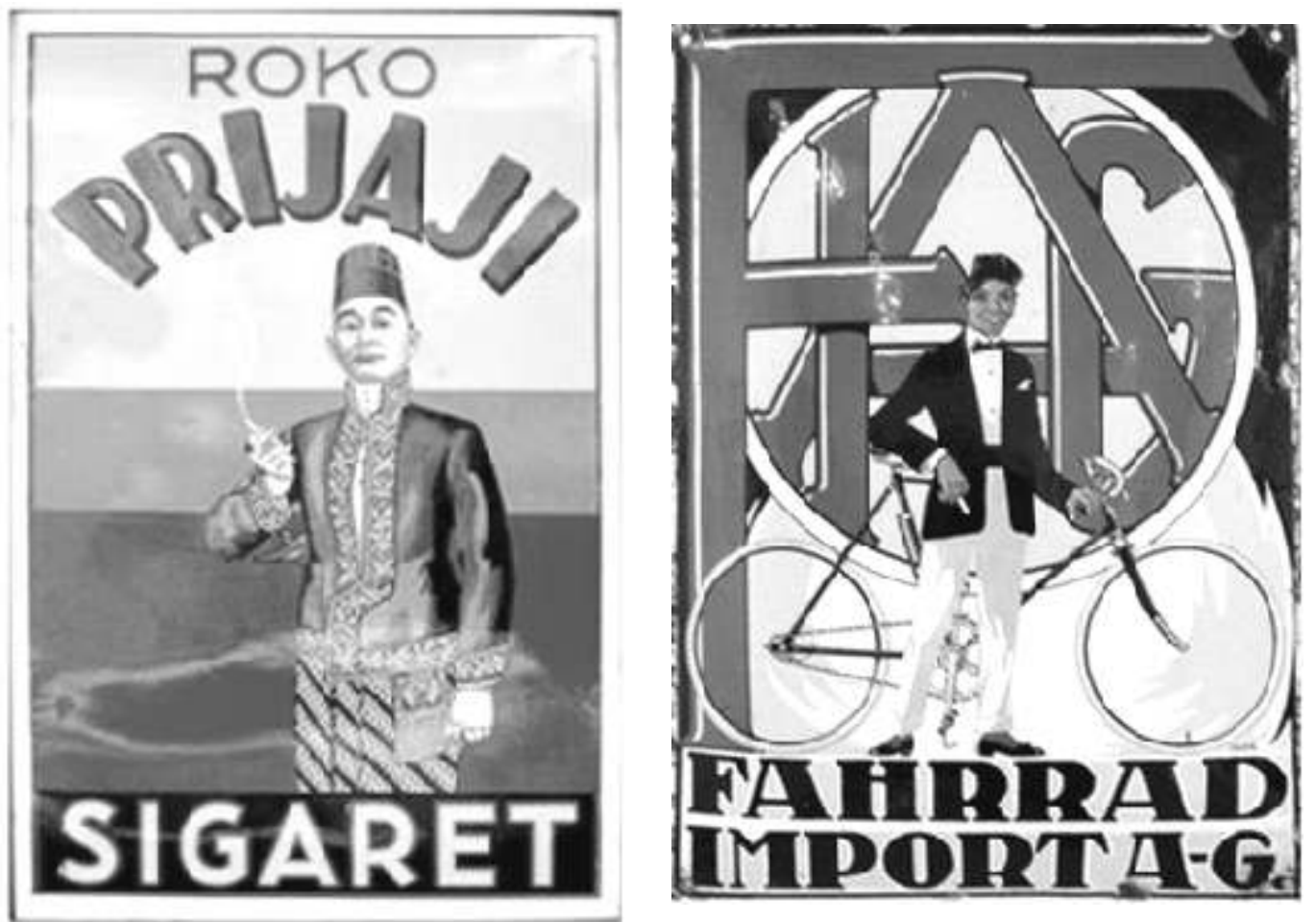

Gambar 5a-b: Performa iklan enamel dengan idiom masyarakat pribumi dengan penampilan yang menunjukkan bahwa mereka berada di strata kelompok yang dianggap sebagai kelas menengah atas.

Gambar 5a : Menampilkan priyayi sebagai kelompok masyarakat strata atas di lingkungan pribumi Jawa sebagai penarik konsumen.

Gambar $5 b$ : Menampilkan model orang pribumi bergaya barat, berupa jas serta celana panjang serta sepatu pantofel dan dasi kupu-kupu (pengaruh dari jas tuxedo kaum elit kulit putih) yang pada awal abad ke-20 jenis pakaian barat diadopsi dengan adanya keterbukaan terutama bagi masyarakat yang sempat menyenyam pendidikan di Belanda.

berjalan tanpa harus menentang kestabilan hubungan kolonial.

\section{Iklan Enamel dalam Konteks Perkotaan Modern}

Awal keberadaan enamel dipakai sebagai penanda kebedaan toko atau produk. Enamel dipakai sebagai name board atau papan nama perusahaan atau produk-produk yang dijual di gedung atau toko yang memajangnya. Sehingga tidak heran jika dikemudian hari enamel diterapkan menjadi bentuk iklan karena sanggup memenuhi imajinasi kolektif masyarakat di perkotaan modern yang menganggap bahwa iklan jenis ini cocok untuk sebagai media iklan yang dipasang di luar ruang. Awalnya iklan enamel hanya berupa pesan tekstual yang terdiri dari deretan tiporgafi yang disusun dengan menggunakan satu jenis type face dan lebih berisi informasi akurat saja, bahkan beberapa diantaranya terasa kurang memperhatikan estetika desain. Pada perkembangan berikutnya visualisasi iklan enamel berkembang menurut apropriasi imajiner perubahan pembentukan identitas dan 
gaya hidup bagi target audience (Maier, 2005:270271) terutama di perkotaan. Hal ini karena dibarengi oleh pertambahan berbagai varian barang komoditas serta selera masyarakat yang semakin berkembang sehingga dibutuhkan penggambaran bentuk visual yang semakin menarik.

Ledakan penggunaan iklan enamel ditandai dengan ekspansi atau pengembangan industri berskala besar. Hal ini yang kemudian memunculkan berbagai alat atau mesin dalam skala besar dan cepat untuk kemudian diaplikasikan pada pembuatan barang-barang baru yang menggantikan alat-alat seadanya yang digunakan sebelumnya. Seperti sepeda dan kendaraan bermotor menggantikan tenaga hewan yang biasa digunakan untuk transpotasi darat, mesin jahit mempermudah produktivitas sandangan pakaian, hingga benda-benda tajam seperti gergaji, gunting, pisau, obeng, kapak dan sebagainya yang menggantikan pisau sederhana. Kereta api dan trem yang menjadi public transportation juga sekaligus digunakan untuk menempel iklan enamel pada sisi-sisi badannya.

Iklan enamel di Hindia umumnya dipasang pada dinding-dinding bangunan besar, sudut toko, stasiun kereta api dan pada tiang-tiang yang berada di jalan raya atau pusat kota. Penempatan pada tiang-tiang dilakukan untuk mengoptimalisasi ruang karena dapat dimanfaatkan pada dua sisi atau bolak-balik. Umumnya tiap sisi memiliki kesamaan bentuk visual, namun tak jarang jenis produk yang diiklankan tiap sisinya berbeda satu sama lain. Pada umumnya peredaran iklan enamel berada di pusat kota atau pusat perdagangan Hindia seperti pada beberapa wilayah dan sektor perdagangan utama seperti 'Weltevreden' di Batavia (kini daerah
Jakarta pusat), 'Bojong Raya' di Semarang, 'Malioboro' di Yogyakarta, 'Tunjungan' di Surabaya, 'Braga' di Bandung dan di sekitaran alun-alun Malang. Daerah tersebut pada umumnya dekat dengan kawasan kantor pemerintahan yang sekaligus memudahkan mobilisasi kekuasaan dan juga dekat dengan simbol modern.

Menarik untuk dicermati adalah daerah Pecinan yang sekaligus sebagai sentra perdagangan yang pada awal abad 20 semakin bertumbuhan. Daerah atau perumahan pecinan merupakan kawasan sibuk yang menyediakan segala kebutuhan daerah di sekitarnya. Pecinan ini, pada kota-kota dengan keraton menjadi kekuatan baru dari sebuah wilayah yang telah bergeser dari keraton-centris menjadi (lebih cederung) jalanjalan dengan atribut pasar dan pusat perdagangan lainnya yang umumnya dimiliki oleh kelompok Tionghoa (Kusno, 2012:51-58).

Fleksibilitas kelompok Tionghoa dalam mengorganisir kepentingan berdagangnya terutama setelah pada tahun 1910 diterbitkannya peraturan "Gelijkgesteld" yang berarti 'kesetaraan' (Elliott, 2004:120). Peraturan ini berisi bagi anak atau keturunan Tionghoa yang lahir di Hindia menjadi atau masuk ke golongan kelas dua atau setingkat dibawah Eropa. Kelompok Tionghoa di daerah pecinan yang sebagian besar lokasinya berada di pinggir jalan raya, kemudian yang menjadi sentra perdagangan menjadi kekuatan baru yang menghidupkan perekonomian kota.

Kepopuleran gaya Art Deco seperti yang diadopsikan iklan enamel Java Bier (gambar 5) sekaligus perlambangan dari kesan dinamis sehingga desainer perlu menambahkan gambar sinar yang memancar yang dibuat dengan garis garis yang tegas diatas bangunan memberikan kesan modern serta gaya hidup yang anggun. 


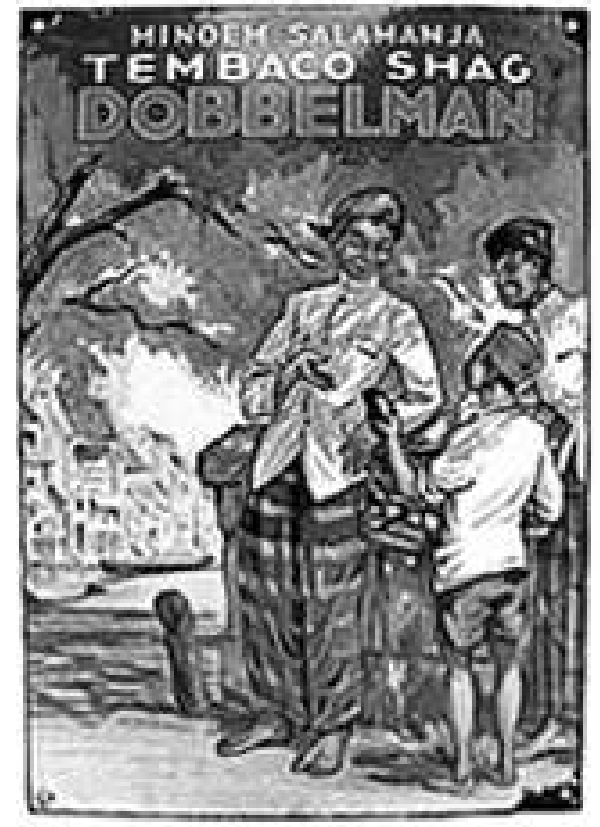

Gambar 5: Performa iklan enamel produk tembakau dengan merk dagang Dobbelman yang menggunakan idiom lokal dengan latar belakang pecinan ini menjadi bukti tentang bagaimana masyarakat saling interaksi yang digambarkan dengan atribut pakaian yang digunakannya
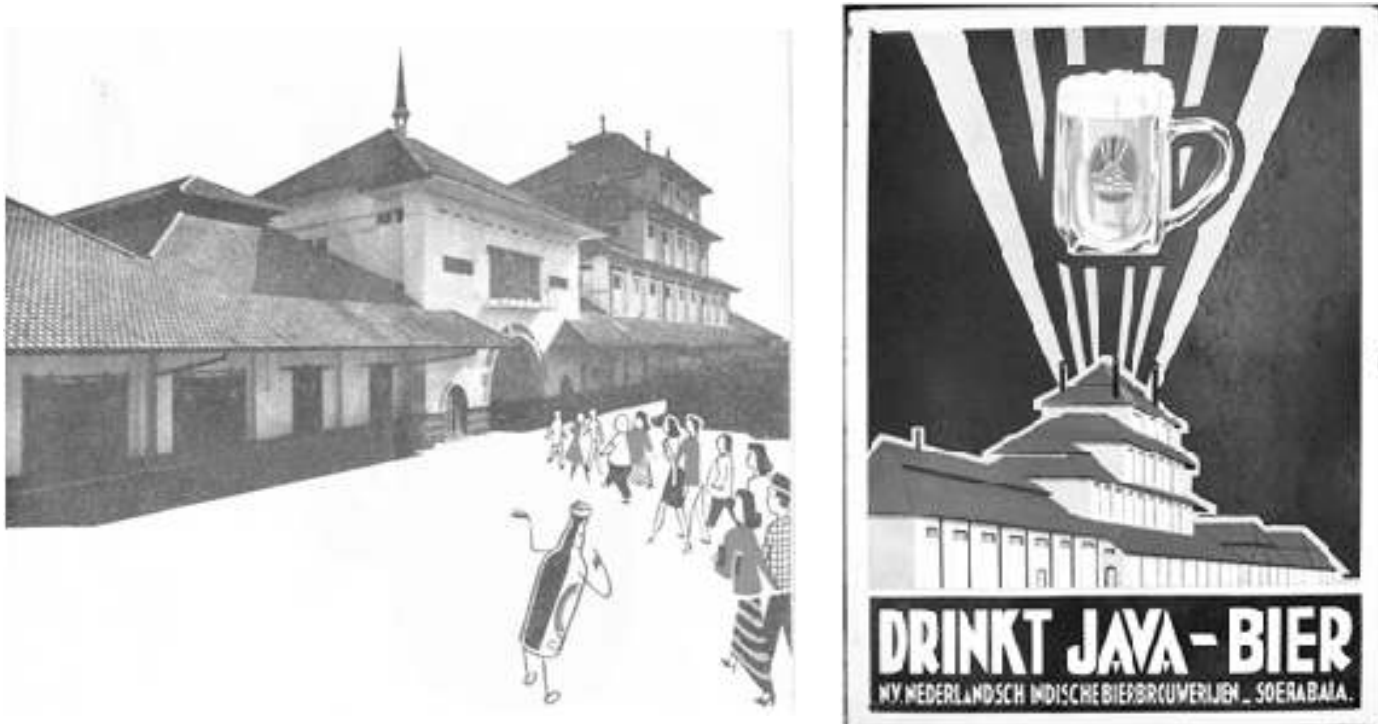

Gambar 5: Gedung arsitek pabrik Java Bier di Surabaya yang bergaya Art deco mengilhami kreator untuk mengaplikasikannya pada iklan sekaligus logo Java Bier 


\section{Kesimpulan}

iklan enamel adalah cermin dari relasi dan interaksi makna serta nilai-nilai dalam suatu sistem sosial kemasyarakatan. Iklan enamel juga merupakan dokumen bersejarah terselamatkan yang pernah semarak menghiasi kota-kota dunia termasuk di wilayah nusantara menjadi sebuah artefak seni mewakili seni visual, khususnya dalam konteks desain komunikasi visual dimana desain merupakan produk kebudayaan hasil dari dinamika sosial. Selain itu iklan enamel juga berperan sebagai elemen yang mampu merekfleksikan hubungan antar masyarakat pendukungnya dan sesuai semangat zamannya.

Kehadiran iklan enamel memang sangat ditentukan campur tangan pihak asing terutama pemerintah kolonial Belanda, namun pada dasarnya idiom visual yang kemudian dihadirkan merepresentasikan adanya bukti sangat kongkrit bagaimana suatu dialog antara kebudyaan saling transfer satu sama lain hinga menjadi satu hibrida kebudayaan yang dinamis. Dari iklan enamel kita dapat melihat perubahan sektor kehidupan yang terjadi pada masyarakatnya terutama modernitas di kota-kota baru yang bertumbuhan di Jawa pada awal abad ke 20.

Peletakan enamel berada pada tempattempat strategis seperti di daerah perdagangan atau pasar, toko-toko serta agen penjualan merepresentasikan kehidupan perekonomian yang bergejolak di tengah kota. Konsep iklan enamel adalah tentang sebuah media luar ruang yang juga masih disepakati hingga kini. Oleh karena itu, iklan enamel menjadi sebuah peradaban iklan media luar ruang yang kemudian mengilhami kehadiran bentuk media lain yang hadir setelahnya. Dengan perbedaan penerapan pada teknologi pembuatannya, tercipta papan reklame atau billboard yang terdiri dari poster panel, paited bulletin, hingga berbentuk olah digital yang sedang marak dewasa ini.

(Makalah disajikan untuk Diskomfest 5 di Jogja National Museum (JNM) pada tanggal 1 Juni 2013) 


\section{Daftar Pustaka}

Bagleer, Christophe \& Morley, Andrew. 1979. Street Jewellery: A History of Enamel Advertising Signs. Great Britain: New Cavendish Books

Gouda, Frances. 2007. Dutch Culture Overseas: Praktik Kolonial di Hindia Belanda, 1900-1942. Jakarta: Serambi

Kusno, Abidin. 2012. Zaman Baru Generasi Baru: Sebuah Catatan Arsitektur. Yogyakarta: Penerbit Ombak

Maier, Henk. 2005. Pusaran Air dan Listrik: Modernitas di Hindia. dalam Outward Appearances: Tren, Identitas, Kepentingan Henk Schulte Nordholt (ed). Yogyakarta: LKiS

Mrazek, Rudolf. 2006. Engineers of Happy Land: Perkembangan Teknologi dan Nasionalisme di Sebuah Koloni. Jakarta: Yayasan Obor

Nordholt, Henk Schulte. 2011. Modernity and Cultural Citizenship in the Nedherlands Indies: An Illustrated Hypothesis dalam Journal of Southeast Asian Studies pp 435-457. Singapore: National University of Singapore

Riyanto, Bedjo. 2000. Iklan Surat Kabar dan Perubahan Masyarakat di Jawa Masa Kolonial (1870-1915). Yogyakarta: Tarawang

Taylor, Jean Gelman. 2005. Kostum dan Gender di jawa Kolonial Tahun 1800-1940 dalam Outward Appearances: Tren, Identitas, Kepentingan Henk Schulte Nordholt (ed). Yogyakarta: LKiS 